\title{
Annealing of Platinum for Thermometry
}

\author{
Robert J. Corruccini
}

\begin{abstract}
Experiments are described on the annealing of platinum wire in which the coefficient of resistance and thermal electromotive force were used as criteria of the physical state of the metal. It was found that platinum wire of the highest available purity almost completely recovers its electrical properties at a temperature as low as $300^{\circ} \mathrm{C}$, although a slight further recovery occurs with increase of annealing temperature up to $1,450^{\circ} \mathrm{C}$. On quenching heated wires in various gaseous media, changes in the electrical properties occur that are greater the more rapid the quenching and that are similar to the effect of strain.

The electrical properties of dilute alloys of gold, silver, and copper in platinum were measured. Contrary to prediction, the copper and silver alloys were thermoelectrically positive to platinum at ordinary temperatures. Thus far, no impurity other than gold has been found to lower the thermoelectric power of platinum.

It is apparently not possible to represent the kinetics of annealing in terms of a temperature activated process having a single value of activation energy. This result is interpreted in terms of the diffusion of dislocations.
\end{abstract}

\section{Introduction}

The metal, platinum, is used in resistance thermometers and in platinum versus platinum-rhodium thermocouples. These types of thermometers, when certain specifications are met, are used to define temperatures on the International Temperature Scale in the range -182.97 to $+1,063^{\circ} \mathrm{C}[1] .^{1} \mathrm{Be}-$ cause both the resistivity and thermal electromotive force (emf) of platinum depend on the physical condition, the annealed condition is specified for platinum to be used in thermometry. This condition is produced by heating and is characterized by decreased tensile strength, hardness, and thermoelectric power and by increased coefficient of resistance compared to cold-drawn or cold-rolled platinum.

The published data on the conditions necessary for annealing are diverse, because the annealing temperature is a function of the amount of deformation in cold-working and the purity of the metal. ${ }^{2}$ Thus, Wise and Vines [2] showed that there was an inverse relation between the amount of deformation produced in cold-rolling platinum to various degrees and the temperature required to restore the metal in $15 \mathrm{~min}$ to the hardness characteristic of annealed platinum. Earlier work by Tammann and Dreyer [3] failed to show such an effect for platinum or palladium, although it was demonstrated that the temperature required for recovery of the minimum hardness and resistivity of silver, copper, and gold varied inversely with the amount of previous deformation. A similar variation in the temperature for recovery of the thermoelectric power of silver was demonstrated by Tammann and Bandel [4]. Feussner [5] showed that the minimum annealing temperature of platinum is raised by additions of impurities.

\footnotetext{
1 Figures in brackets indicate the literature references at the end of this paper. 2 Evaluation of published data on the conditions for annealing platinum is frequently difficult because information on the amount of deformation and the purity is not given. The purity of thermometric platinum is conveniently specified by a coefficient of resistance, in particular by the average coefficient over specified by a coefficient of resistance, in particular by the average coefficient over
the interval, $0^{\circ}$ to $100^{\circ} \mathrm{C}$, which is defined as $\left(R_{100}-R_{0}\right) / 100 R_{0}=\alpha$. It would be the interval, $0^{\circ}$ to $100^{\circ} \mathrm{C}$, which is defined as $\left(R_{100}-R_{0}\right) / 100 R_{0}=\alpha$. It would be
desirable to have the value of this quantity always stated as a figure of merit for platinum of thermometric quality.
}

The International Temperature Scale [1] recommends that platinum for thermometry should be annealed in air above the maximum temperature at which it is to be used $\left(450^{\circ} \mathrm{C}\right.$ or higher for standard resistance thermometers and about $1,100^{\circ} \mathrm{C}$ for standard thermocouples).

Since 1935, platinum versus platinum-rhodium thermocouples submitted to the Bureau for calibration have been annealed for $1 \mathrm{hr}$ at $1,450^{\circ} \mathrm{C}$ before calibration, the temperature $1,450^{\circ}$ being approximately the maximum temperature of calibration. The wires are annealed by hanging them between two binding posts in air and passing an electric current through them. A previous article [6] offers the following comments on this practice.

"There is some question as to the optimum temperature or length of time at which such couples should be annealed to produce the most constant characteristics in later use. As a matter of fact, there is some question as to whether annealing for for more than a few minutes is harmful or beneficial. Most of the mechanical strains are relieved during the first few minutes of heating at 1,400 to $1,500^{\circ} \mathrm{C}$, but it has been claimed that the changes in the thermal emf of a couple in later use will be smaller if the wires are heated for several hours before calibration and use. The principal objection to annealing thermocouples for a long time at high temperatures aside from the changes in emf taking place, is that the wires are weakened mechanically as a result of crystal growth."

The lowest annealing temperature that has been advocated for thermometric platinum is $400^{\circ} \mathrm{C}$ [7]. Brenner states, "It was found that chemically pure platinum wire can be completely annealed at $400^{\circ} \mathrm{C}$ in one hour. Wire annealed slowly at this temperature in air (by heating it in a platinum dish in a furnace, not by resistance heating) shows an improved behavior with respect to contamination in subsequent service as compared to wire annealed (by electrical heating) at $1,450^{\circ} \mathrm{C}$."

In an unpublished investigation at this Bureau in 1947, C. H. Meyers found that 0.003-in.-diameter 
TO JUNCTIONS IN ICE BATH

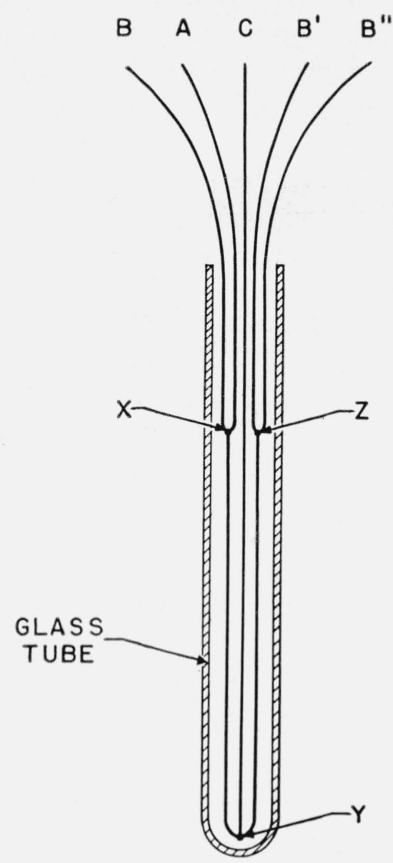

FIgURE 1. Schematic diagram of sample and leads.

AXYZ is the sample. Terminals $\mathrm{B}-\mathrm{A}-\mathrm{B}^{\prime}-\mathrm{B}^{\prime \prime}$ were used when the portion $\mathrm{XYZ}$ was to be used as a four-lead resistor. Terminals A-C were used for determination of the thermal emf of portion $\mathrm{AY}$ versus the reference platinum wire $\mathrm{CY}$

platinum resistance-thermometer wire (cross-sectional area reduced $99+\%$ in drawing) was almost completely annealed within $5 \mathrm{~min}$. at $500^{\circ} \mathrm{C}$. After heating for a few minutes in air at about $1,000^{\circ} \mathrm{C}$, the value of $\alpha\left(=\left[R_{100}-R_{0}\right] / 100 R_{0}\right)$ decreased but increased again upon subsequent heating at $500^{\circ}$ or $600^{\circ} \mathrm{C}$. It was pointed out by Meyers that this effect would be of importance in using platinumresistance-thermometers at high temperatures.

The present investigation had a twofold purpose at the start: (1) To find whether annealing for $1 \mathrm{hr}$ at $1,450^{\circ} \mathrm{C}$ causes any further change in the electrical properties of platinum that has already been annealed at a lower temperature, and (2) to investigate the reversible decrease of the coefficient of resistance due to heating that was found by Meyers. An experimental arrangement was used that permitted measurement of both the coefficient of resistance, $\alpha$, and the thermal emf (versus an arbitrary reference material) of samples of platinum after each of a series of heat treatments. Because the changes in $\alpha$ and thermal emf are related, measurement of both properties provides a valuable experimental check on the results. Since these electrical properties are sensitive to impurities, care was taken to avoid contamination of the platinum. During the course of this work, it was decided to investigate the effects of the impurities, gold, silver, and copper on the electrical properties of platinum and also the kinetics of annealing. These subjects are discussed later in separate sections.

\section{Experimental Methods}

Figure 1 shows the arrangement of the sample and leads used for most of the measurements. The length AXYZ was the sample. At $\mathrm{X}$ was welded a platinum lead $\mathrm{BX}$, and at $\mathrm{Z}$ were welded two platinum leads $\mathrm{B}^{\prime} \mathrm{Z}, \mathrm{B}^{\prime \prime} \mathrm{Z}$. The leads $\mathrm{BX}, \mathrm{B}^{\prime} \mathrm{Z}, \mathrm{B}^{\prime \prime} \mathrm{Z}$ were platinum of ordinary quality. The wire $\mathrm{CY}$ was a reference wire for the measurement of thermal emf. The thermal emf of the sample versus the reference wire was measured, using terminals A-C. The length XYZ (16 in.) of the sample served as the element of a four-lead resistor for the determination of $\alpha$, using terminals $\mathrm{B}-\mathrm{A}-\mathrm{B}^{\prime}-\mathrm{B}^{\prime \prime}$. Most of the measurements were made using 0.020 -in. thermocouple-grade platinum wire. The reference wire CY was an annealed 0.020 -in. thermocouple-grade platinum wire. For measurement of the electrical properties, the sample, with leads attached as shown in figure 1, was inserted into a glass tube of $15-\mathrm{mm}$ inside diameter with the wires separated by mica partitions.

The connections between the platinum wires and the copper leads to the measuring circuit were in an ice bath, except for sample 3 . With this sample no thermal emf measurements were made, hence the reference wire CY was absent and the copper leads were soldered to short lengths of the four platinum leads inside the glass sample-tube. All electrical measurements were made with a Wenner thermocouple potentiometer. The resistance of the samples of 0.020 -in. wire was about $0.2 \mathrm{ohm}$ at the ice point. For measuring the resistance of the 0.020 -in. wire, a current of 20 ma was used. It was found that the effect of the heating due to this measuring current was negligible. As the voltage drop across the resistor was only about $4 \mathrm{mv}$, care was taken to minimize residual emf in the system. ${ }^{3}$ All connections between the potentiometer and the sample leads were of copper. By means of a four-pole double-throw switch of low contact resistance, the currents in the potentiometer and the sample could be reversed simultaneously. By averaging the emf readings obtained in this way, the residual emf in the sample and the measuring circuit was canceled out (to the extent that it remained constant throughout successive reversals). As the coefficient of resistance was of greater interest than the absolute values of resistance, the potentiometer was calibrated in terms of an arbitrary unit by a method of internal comparison of coils. ${ }^{4}$ With this calibration, emf ratios, and hence $\alpha$, could be obtained accurately without knowledge of the relation between the arbitrary unit of emf used and the absolute unit of emf.

\footnotetext{
${ }^{3}$ By "residual" emf is meant the emf that would still exist in the sample and leads were the current through the sample reduced to zero, as well as the emf that the potentiometer would register if the input terminals were short-circuited with copper. These are largely, if not entirely, thermal. The former result mostly from strain inhomogeneity in the leads in regions where a temperature gradient exists and may amount to as much as several microvolts. The latter usually results from lack of temperature uniformity throughout the galvanometer circuit. In these experiments, it was negligible.

4 For an analogous method employed with bridges see Wheatstone bridges and some accessory apparatus for resistance thermometry by E. F. Mueller, Bul. BS 13, 553 (1916-17),S288.
} 
Routine measurements of the thermal emf of test wires versus the Bureau's platinum thermoelectric standard, $\mathrm{Pt}-27$, are usually made with the wires inserted in porcelain insulating and protection tubes with the hot and cold junctions at $1,200^{\circ}$ and $0^{\circ} \mathrm{C}$, respectively. For the present measurements, it was desired to evaluate the effect of strain on the thermal emf. In order that annealing should not occur during the measurement, a hotjunction temperature lower than the lowest reported temperature for rapid annealing of platinum $\left(400^{\circ}\right.$ C) was required. For this measurement the sample tube was lowered into a vertical tube-furnace. Measurements of all except the hard-drawn wires were made at $300^{\circ}$ or $400^{\circ} \mathrm{C}$. Experiments showed that, with the time of measurement used, the thermoelectric power of these wires was independent of the hot-junction temperature over the above range. The measurements with hard-drawn wires (samples 5 and 7 ) were made at either $100^{\circ}$ or $200^{\circ}$ $\mathrm{C}$, as the initial rate of change of electrical properties of such wire due to annealing is rapid at $300^{\circ} \mathrm{C}$ or above.

In measuring the thermal emf, a switch was used to reverse simultaneously the unknown emf and the potentiometer current and thus eliminate the effect of residual emfs in the measuring circuit. Careful handling of the sample and leads is important, since a portion of wire that has been coldworked by bending may have thermoelectric properties differing slightly from those of the unworked portion. If the region where the resulting physical inhomogeneity exists is placed in a temperature gradient, it becomes the seat of a thermal emf, which may amount to as much as several microvolts, and, in these experiments, was difficult to reduce below $0.1 \mu \mathrm{v}$. The effect may be detected by changing the temperature distribution along the sample, for example, by varying the immersion of the sample in the ice bath, steam bath, or furnace. If the measured thermal emf remains constant in such a test, it is probable (though not certain) that there is no emf due to inhomogeneity in the wires. The effect was minimized by avoiding bending of the wires AXY and CY. The most reliable measurements of thermal emf were those made after annealing the sample in the furnace. After such annealing, the sample was raised a few inches in the furnace for the thermal emf measurement, thus bringing annealed (homogeneous) wire into the region of the temperature gradient at the top of the furnace while keeping the junction $\mathrm{Y}$ in the isothermal hot zone. In cases where the properties of the lower part of the sample wire AXY were changed by annealing in the furnace, while the part outside the furnace remained unchanged, a correction, which in most cases was nearly negligible, was applied to the measured thermal emf to make it correspond to its value if the annealing had extended all the way to the cold junction.

All values of emf were measured to the nearest 0.02 $\mu \mathrm{v}$. Because of the difficulty of completely eliminating residual emf in the platinum, the reported thermal emfs may be in error by as much as 0.1 to $0.2 \mu \mathrm{v}$. The resistance measurements were reproducible within about 1 part in $10^{5}$ (corresponding to a few hundredths of a microvolt out of a measured emf of $4,000 \mu \mathrm{v})$. Values of $\alpha$ measured in this investigation may be in error by as much as $5 \times 10^{-7}$.

With the samples and measuring equipment used, the thermal emf provided a more sensitive index of physical changes in the wire than did the coefficient of resistance. However, the latter is a more reliable index because of the cancellation of the residual emfs by reversal of the measuring current.

At first, annealing at $1,450^{\circ} \mathrm{C}$ was carried out in vacuum in order to avoid atmospheric contaminants. This was done by removing the sample from its tube and suspending it from binding posts in a bell jar, using leads $A$ and either $B^{\prime}$ or $B^{\prime \prime}$ to carry the annealing current. The other leads and the reference wire CY remained attached but carried no current and were not heated appreciably in this process. The residual pressure in the bell jar was in the range 1 to $10 \mu$ of mercury. A liquid-air trap was used to remove mercury vapor originating with the mercury-vapor pump. Following such annealing the sample was carefully mounted in its glass tube with the tube open to the air, and the coefficient of resistance and the thermal emf were measured. Following the first anneal of 0.020 -in. wire at $1,450^{\circ}$ $\mathrm{C}$ in vacuum (table 1 , sample 4 item $\mathrm{C}$ ), it was found that $\alpha$ had decreased slightly but that the decrease was very much less than Meyers had found with 0.003 -in. wire in air. The rate at which the wire had cooled from $1,450^{\circ} \mathrm{C}$, following cutting off of the annealing current, was relatively slow, due, on the one hand, to the absence of convective heat loss and, on the other hand, to the relatively large size of the wire. It was realized that the effect noted by Meyers might depend on the rate at which the wire was cooled from high temperatures. In subsequent experiments, the rate of cooling was varied by filling the bell jar with air or helium at about atmospheric pressure for the cooling period. Later it was found that annealing could be carried out in the open air of the laboratory without contamination, and more rapid cooling was obtained by directing a fan at the sample. In order to test the reversibility of the changes in electrical properties produced by these treatments, the samples were annealed at $500^{\circ} \mathrm{C}$ in air (in the tube-furnace) following each high-temperature electrical anneal, as Meyers' experiments had indicated that the limiting maximum value of $\alpha$ would be attained after such treatment.

\section{Materials}

Samples 3 and 4 were from different lots of platinum wire of thermocouple grade that had been annealed for $1 \mathrm{hr}$ at $400^{\circ} \mathrm{C}$ by the manufacturer. Sample 5 was from one lot and samples 7,8 , and 9 were from another lot of thermocouple platinum, both of which had been furnished hard-drawn (crosssectional area reduced $99+\%$ in drawing). Two 
other samples of annealed 0.020-in. platinum wire from the same source as the other samples gave results similar to those with sample 4 but were omitted from this paper because the measurements were preliminary and were considered less reliable. All samples used in this investigation were furnished by the Sigmund Cohn Corp.

\section{Results}

The various experiments relating to the initial objectives of this investigation are listed in table 1 in the order in which they were performed on each wire.

In order to put the values of the thermal emf of the samples versus the reference wire on a common basis, they have been calculated for a hot-junction temperature of $400^{\circ} \mathrm{C}$ (next to last column, table 1). In the last column of table 1 are given values of the thermal emf of the samples versus Pt-27 based on a measurement of the thermal emf of the reference wire versus $\mathrm{Pt}-27$. In computing the last two columns of table 1 , it was assumed that the thermal emf was linear with temperature between $0^{\circ}$ and $1,200^{\circ} \mathrm{C}$.

Effect of annealing at $1,450^{\circ}$. With regard to the first objective of this investigation, the results in table 1 indicate that hard-drawn platinum wire of high purity almost completely recovers its electrical properties after $1 \mathrm{hr}$ at $400^{\circ}$ or $500^{\circ} \mathrm{C}$, though a slight further recovery occurs with increase of the

TABLE 1. Effect of various treatments on the electrical properties of platinum

"Cooling time" is the time required for the sample to cool to the disappearance of incandescence.

\begin{tabular}{|c|c|c|c|c|c|}
\hline Treatment & $R_{0}$ & $R_{100}-R_{0}$ & $\left.=\frac{R_{100}-R_{0}}{100 R_{0}}\right)$ & $E_{0^{\circ}{ }^{\circ}{ }^{\circ}{ }^{\circ} \mathrm{C}, \text { ref }}$ & $E_{0^{\circ}}^{1.200^{\circ} \mathrm{va}, \text { Pt. } 27}$ \\
\hline \multicolumn{6}{|c|}{ Sample 4, 0.020-in. diameter } \\
\hline 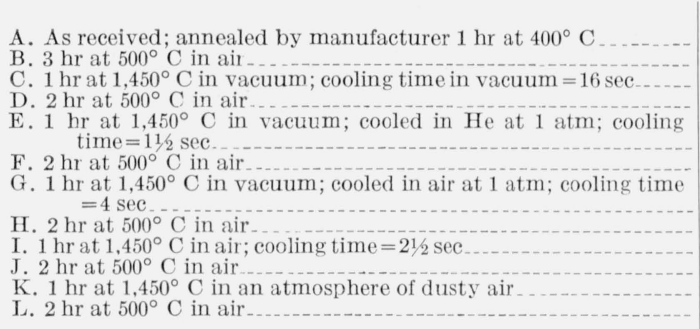 & $\begin{array}{l}\text { Ohms } \\
0.189162 \\
.189092 \\
.189248 \\
.189228 \\
.189533 \\
.189302 \\
.189531 \\
.189396 \\
.190078 \\
.189933 \\
.190495\end{array}$ & $\begin{array}{l}\text { Ohms } \\
0.074248 \\
.074245 \\
.074301 \\
.074298 \\
.074328 \\
.074333 \\
.074373 \\
.074385 \\
.074585 \\
.074584 \\
.074812\end{array}$ & $\begin{array}{r}0.0039251 \\
.0039265 \\
.0039261 \\
.0039263 \\
.0039216 \\
.0039267 \\
.0039241 \\
.0039275 \\
.00039239 \\
.0039268 \\
.0039272\end{array}$ & $\begin{array}{r}\mu v \\
+0.8 \\
.0 \\
-.5 \\
-.7 \\
+2.2 \\
-0.7 \\
+.6 \\
-.9 \\
+.8 \\
-1.1 \\
+1.5 \\
-1.2\end{array}$ & $\begin{array}{c}\mu v \\
-4.3 \\
-6.7 \\
-8.2 \\
-8.8 \\
-0.1 \\
-8.8 \\
-4.9 \\
-9.4 \\
-4.3 \\
-10.0 \\
-2.2 \\
-10.3\end{array}$ \\
\hline \multicolumn{6}{|c|}{ Sample $5 ; 0.003$-in. diameter } \\
\hline $\begin{array}{l}\text { A As received; hard-drawn; reduction of eross-sectional area in } \\
\text { drawing =99+\% } \\
\text { B. } 2 \mathrm{hr} \text { at } 500^{\circ} \mathrm{C} \text { in air- } \\
\text { C. } 15 \mathrm{~min} \text { at } 1,450^{\circ} \mathrm{C} \text { in air; cooling time }=\text { about } 0.1 \mathrm{sec} \\
\text { D. } 2 \mathrm{hr} \text { at } 500^{\circ} \mathrm{C} \text { in air }\end{array}$ & $\begin{array}{l}\text { 5. } 119 \\
\text { 4. } 9816 \\
5.1460 \\
5.1168\end{array}$ & $\begin{array}{l}\text { 1. } 954 \\
\text { 1. } 9548 \\
\text { 2. } 0001 \\
\text { 2. } 0091\end{array}$ & $\begin{array}{l}0.00382 \\
.0039240 \\
.0039023 \\
.0039265\end{array}$ & $\begin{array}{c}+96 \\
+3.6 \\
-\end{array}$ & $\begin{array}{r}+280 \\
+5 \\
-\end{array}$ \\
\hline \multicolumn{6}{|c|}{ Sample $7 ; 0.020$-in. diameter } \\
\hline 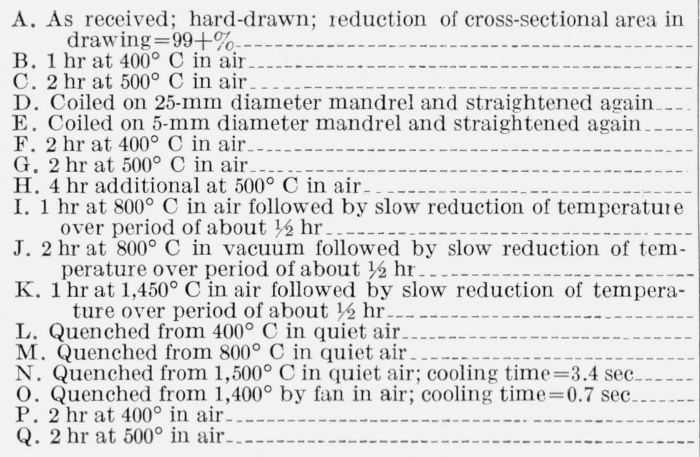 & $\begin{array}{r}0.1936 \\
.190437 \\
.190412 \\
.190730 \\
.193569 \\
.193410 \\
-.193387 \\
.193334 \\
.193359 \\
.193799 \\
.193790 \\
.193755 \\
.194034 \\
.194213 \\
.193940 \\
.193880\end{array}$ & $\begin{array}{r}0.07472 \\
.077774 \\
.074761 \\
.074882 \\
.075899 \\
.075927 \\
.075932 \\
.075934 \\
.075931 \\
.076107 \\
.076108 \\
.076112 \\
.076143 \\
.076132 \\
.076144 \\
.076141\end{array}$ & $\begin{array}{r}0.00386 \\
.0039264 \\
.0039262 \\
.0039261 \\
.0039210 \\
.0039257 \\
.0039264 \\
.0039276 \\
.0039269 \\
.0039271 \\
.0039273 \\
.0039278 \\
.0039242 \\
.0039200 \\
.0039261 \\
.0039272\end{array}$ & \begin{tabular}{c}
+63 \\
+0.3 \\
+.1 \\
\hdashline+3.1 \\
+1.6 \\
+1.1 \\
+1.0 \\
-0.5 \\
-.2 \\
-1.1 \\
-0.9 \\
-1.3 \\
+1.0 \\
+2.5 \\
-0.4 \\
-1.2
\end{tabular} & $\begin{array}{r}+182 \\
-5.8 \\
-6.4 \\
-+2.6 \\
-1.9 \\
-3.4 \\
-3.7 \\
-8.2 \\
-7.3 \\
-10.0 \\
-9.4 \\
-10.6 \\
-3.7 \\
+0.8 \\
-7.9 \\
-10.3\end{array}$ \\
\hline \multicolumn{6}{|c|}{ Sample $3 ; 0.020$-in. diameter } \\
\hline $\begin{array}{l}\text { A. As received; annealed by manufacturer for } 1 \mathrm{hr} \text { at } 400^{\circ} \mathrm{C} \\
\text { B. } 1 \mathrm{hr} \text { at } 1,450^{\circ} \mathrm{C} \text { in vacuum followed by } 7 \mathrm{hr} \text { at } 500^{\circ} \text { in air.- } \\
\text { C. } 1 \mathrm{hr} \text { at } 1,450^{\circ} \mathrm{C} \text { in air followed by } 9 \mathrm{hr} \text { at } 500^{\circ} \mathrm{C} \text { in air } \\
\text { D. Cooled from } 1,450^{\circ} \mathrm{C} \text { in helium over period of about } 1 / 2 \mathrm{hr} \\
\text { E. } 4 \mathrm{hr} \text { at } 500^{\circ} \mathrm{C} \text { in air }\end{array}$ & $\begin{array}{r}0.190009 \\
.190032 \\
.190586 \\
.190590 \\
.190581\end{array}$ & $\begin{array}{r}0.074565 \\
.074623 \\
.074845 \\
.074843 \\
.074849\end{array}$ & $\begin{array}{r}0.0039243 \\
.0039269 \\
.0039271 \\
.0039269 \\
.0039274\end{array}$ & - & - \\
\hline
\end{tabular}




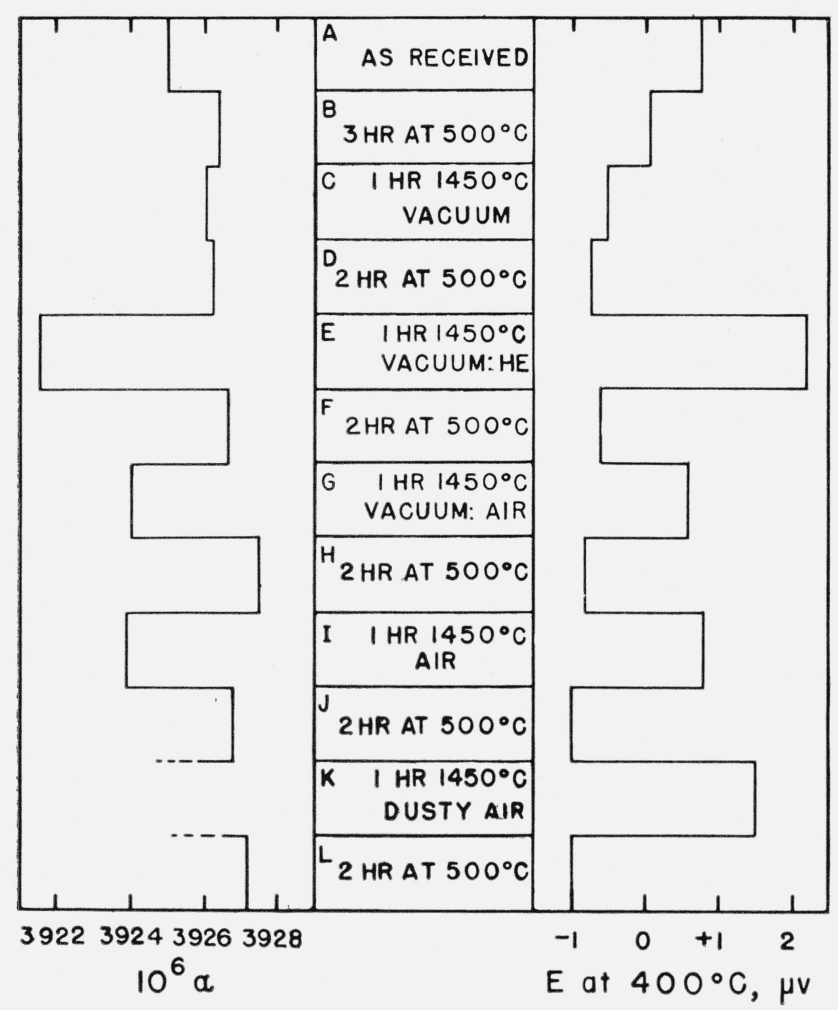

FIGURE 2. Effect of various heat-treatments on the electrical properties of sample 4.

See table 1 for the numerical data and a description of the experimental conditions.

annealing temperature up to $1,450^{\circ}$ C. ${ }^{5}$ However, this conclusion should not be applied without qualification to platinum of lower purity. The initial values obtained for samples 3 and 4 indicate that these were not completely annealed when received. However, this may have resulted from the strain of coiling and other handling that intervened between the manufacturer's anneal and the determination of the initial results in table 1.

Effect of quenching. Figure 2 illustrates graphically the data on sample 4 . It will be noted that with the exception of item $\mathrm{C}$, the simultaneous changes in $\alpha$ and $E$ are of opposite sign and roughly proportional to each other. This proportionality is also displayed in figure 3.

After each quench from $1,450^{\circ} \mathrm{C}$ the values of $\alpha$ and $E$ were restored by the subsequent anneal for 2 hrs at $500^{\circ} \mathrm{C}$ in air to approximately the values 0.003927 for $\alpha$ and $-1 \mu \mathrm{v}$ for $E_{0_{0}^{\circ}}^{400^{\circ}} \mathrm{vs}$ reference wire, the latter value corresponding to $-10 \mu \mathrm{v}$ versus $\mathrm{Pt}-27$ at $1,200^{\circ}$. These values may thus be regarded as limiting values for this very pure platinum in the annealed state. The most extreme values previously

${ }^{5}$ B. G. Dammers (Thesis, Leiden, 1936. A brief summary is given by W. H. Keesom and B. G. Dammers, Physica 2, 1051 (1935)) and W. Meissner (Ann. Phys. [5] 39. 264 (1937)) have reported the existence of an optimum annealing temperature of about $800^{\circ} \mathrm{C}$. According to these authors, a maximum coefficient of resistance was obtained by annealing at this optimum temperature with lower values obtained after annealing at either higher or lower temperatures. This values obtained after annealing at either higher or lower temperatures. This result was not confirmed by the present investigation. Since the variation of coefficient of resistance with annealing temperature was not demonstrated to
be reversible by these authors, it is possible that their samples became contaminated at the higher temperatures.

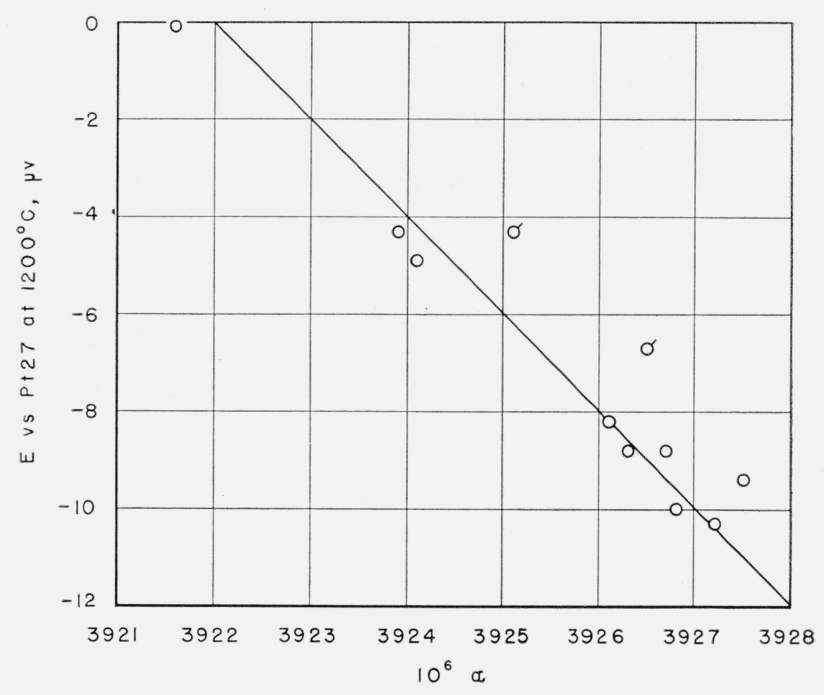

Figure 3. Graph of data on sample 4 showing the proportionality of thermal emf with coefficient of resistance throughout the various heat-treatments.

See table 1 for a description of the experiments. $\sigma$, Before first anneal at $1,450^{\circ}$ $\mathrm{C} ; \mathrm{O}$, on quenching from $1,450^{\circ} \mathrm{C}$ to room temperature at various rates; the diagonal line represents the equation $\alpha=0.003922-0.5 \times 10^{-6} E_{0}^{1}{ }^{\circ}{ }^{200^{\circ}}{ }^{\circ} \mathrm{C}$ Pt. -27 .

recorded at the Bureau were 0.003926 for $\alpha$ and $-8 \mu \mathrm{v}$ for $E_{0^{\circ} \text { vs. }}^{1,200^{\circ}-27}$. Since, in all known cases, impurities lower the coefficient of resistance of platinum and (with the exception of gold) make the emf more positive, it is presumed that the repeated attainment of 0.003927 for $\alpha$ and $-10 \mu \mathrm{v}$ for $E_{0_{0}^{\circ}}^{1,200^{\circ}}{ }_{\text {vs. }} \mathrm{Pt}_{\mathrm{t}-27}$ throughout the measurements with the 0.020 -in. samples indicates that the wire was exceptionally pure and that no appreciable contamination occurred during the experiments. ${ }^{6}$

The decrease in $\alpha$ and increase in $E$ from the above limiting values, which occur on quenching in various atmospheres, are greater the more rapid the quenching. This is shown in table 2 , which summarizes the pertinent data from table 1 . The time of cooling from $1,450^{\circ} \mathrm{C}$ (the temperature was measured with an optical pyrometer assuming an emissivity of 0.30 at the effective wavelength of $0.65 \mu)$ to the dis-

${ }^{6}$ Because the value 0.003927 for $\alpha$ is higher than any previously recorded at this Bureau, the experimental procedure was examined with special care to make sure that the result was not due to an experimental error. As a further check, the value of $\alpha$ for sample 3 was determined on three separate occasions by M. Waxman and of $\alpha$ for sample 3 was determined on three separate occasions by M. Waxman and Johanna Busse of the resistance thermometry group at the Bureau. These determinations involved ways of measuring resistance and of realizing the temperatures that were completely different from those used by the author. A Mueller
bridge was used for the resistance measurement. The value of $R_{0}$ was obtained bridge was used for the resistance measurement. The value of $R_{0}$ was obtained
from measurements at the triple point of water, while the steam point was realized from measurements at the triple point of water, while the steam point was realized sure. On the other hand, the results by the author were obtained, using a potentiometer, an ice bath, and a hypsometer open to the atmosphere. The three comparisons gave the following results:

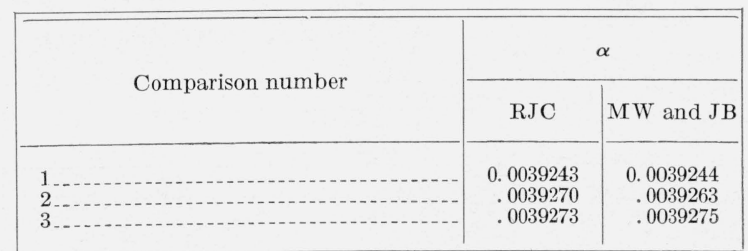

The differences are less than the sum of the individual uncertainties which were about $5 \times 10^{-7}$ for RJC and 2 or $3 \times 10^{-7}$ for $\mathrm{MW}$ and JB. 
TABLE 2. Effect of rate of quenching on electrical properties of platinum

\begin{tabular}{|c|c|c|c|c|}
\hline Treatment a & $\begin{array}{l}\text { Atmosphere } \\
\text { during cooling }\end{array}$ & $\begin{array}{l}\text { Average } \\
\text { cooling } \\
\text { time b }\end{array}$ & $\alpha$ & $E_{0^{\circ}}^{1.200^{\circ}} \quad \mathrm{Pt}-27$ \\
\hline Limiting values obtained following anneal for 2 hours at $500^{\circ} \mathrm{C}$ in & & & 0.003927 & $-10^{\mu \nu}$ \\
\hline $\begin{array}{l}\text { air. } \\
\text { Temperature reduced over a period of about } 1 / 2 \text { hour by gradual } \\
\text { reduction of annealing current. }\end{array}$ & & ea 1,000 & .003927 & -10 \\
\hline Do & Helium, 1 atm ..... & ca 1,000 & .003927 & Not measured \\
\hline Normal cooling after abrupt cutting off of annealing current_-_--.-- & Vacuum (1 micron) & 16 & .003926 & \\
\hline Do & Air $1 \mathrm{~atm}$ & $\begin{array}{l}3 \\
5\end{array}$ & .003924 & -4 \\
\hline $\begin{array}{l}\text { Forced cooling in fan blast after abrupt cutting off of the annealing } \\
\text { current. }\end{array}$ & Air, $1 \mathrm{~atm}$ & 0.7 & $\begin{array}{l}.003922 \\
.003920\end{array}$ & +1 \\
\hline Normal cooling; 3-mil wire & -.--do & ca 0.1 & .003902 & Not measured \\
\hline
\end{tabular}

a Except for last entry, all values are for 0.020-in,-diameter wire.

b Time of cooling from about $1,450^{\circ}$ to disappearance of incandescence.

appearance of incandescence was used as a comparative index of the cooling rate. Table 2 shows that the particular gaseous atmospheres used do not exert an appreciable influence on the electrical properties, and that the rate of cooling alone is of primary importance.

It appears that this effect is an indication of strain produced by the surface of the wires cooling more rapidly than the interior. As is pointed out later, Matthiessen's rule is obeyed throughout the experiments. In other words, the increase in resistivity due to quenching is approximately temperature-independent, and this implies an increase in the residual resistance (resistance at $0^{\circ} \mathrm{K}$ ). Such an increase results from increasing the number of lattice defects and is characteristic of strain due to cold-working.

To examine the extent to which the effect of quenching is analogous to a strain, the experiments upon sample 7 involving coiling and straightening of the wire were made. These results show that annealing at $400^{\circ} \mathrm{C}$ almost completely overcame the effect of a bending strain on $\alpha$, but that the thermal emf was only partially restored and that further decrease in $E$ occurred with stepwise increase of the annealing temperature up to $1,450^{\circ} \mathrm{C}$. Thus the effect on $\alpha$ and $E$ of annealing after a bending strain was not fully consistent with that obtained on annealing after quenching.

In another experiment (not included in table 1) a sample of 0.020 -in. wire was rolled to a thickness of about 0.001 in. It was annealed in a flame between passes. The last reduction in thickness amounted to about 20 percent. It was found that $2 \mathrm{hr}$ at $500^{\circ} \mathrm{C}$ brought $\alpha$ to the value characteristic of complete annealing. The thermal emf was not measured. The maximum value of $\alpha$ obtained with this sample was 0.003908 , indicating relatively low purity.

Matthiessen's rule. The values of $R_{0}$ and $R_{100}-R_{0}$ given in table 1 have been included in order to illustrate the extent to which the resistance changes that result from quenching and annealing obey Matthiessen's rule [8]. This rule may be stated in the following general way: Slight variations in the purity or physical state of a metal cause variations in resis- tivity that are neariy independent of temperature. The rule will be seen to be valid to the extent that the quantity, $R_{100}-R_{0}$, remains constant throughout treatments that cause changes in $R_{0}$. In certain of the experiments, changes in physical state are combined with changes in dimensions of the wire due to coiling or volatilization. The latter effect changes both $R_{0}$ and $R_{100}-R_{0}$ in the same proportion, and here the validity of Matthiessen's rule cannot be determined by simple inspection of the data. In general, the rule is seen to hold approximately, since changes in $R_{100}-R_{0}$ are much smaller than the changes in $R_{0}$ in those experiments where no dimensional change occurred.

Rate of evaporation of platinum. It is known that platinum volatilizes more rapidly in air than in vacuum [9]. This is thought to be due to the formation in air of a volatile oxide that is unstable. This effect is apparent in the data on $R_{0}$ in table 1 . After allowing for the effect of quenching, these data show that the rate of increase of $R_{0}$ at $1,450^{\circ} \mathrm{C}$ is several times greater in air than in vacuum. Assuming that the increases in $R_{0}$ in air are largely due to evaporative decrease of the cross-sectional area of the wire, it is calculated that the rate of volatilization at $1,450^{\circ} \mathrm{C}$ of a wire hanging vertically in air is roughly 20 times the rate of volatilization in vacuum found by Jones, Langmuir, and Mackay [10].

Relation between $\alpha$ and $E$. In the past 15 years, the values of $\alpha$ and $E_{0^{\circ}{ }^{\circ} \text { vs. Pt-27 }}^{1.2{ }^{\circ}}$ have been determined at this Bureau for nearly 100 samples of platinum from various sources. Any differences between these samples may be attributed to differences in purity, as all were annealed for $1 \mathrm{hr}$ at $1,450^{\circ} \mathrm{C}$ in air before testing. The results are plotted as open circles in figure 4. Although there is considerable scattering, much of the data can be represented by the following simple equation, which is represented by the solid straight line in figure 4 . $E$ is in microvolts.

$$
\alpha=0.003922-0.5 \times 10^{-6} E_{0^{\circ} \text { vs. Pt-27. }}^{1,200^{\circ}} .
$$

This relation was noted by Wm. F. Roeser some years ago and is published here for the first time. Unfortunately, there were only a few samples where a single impurity predominated, so that it is not 


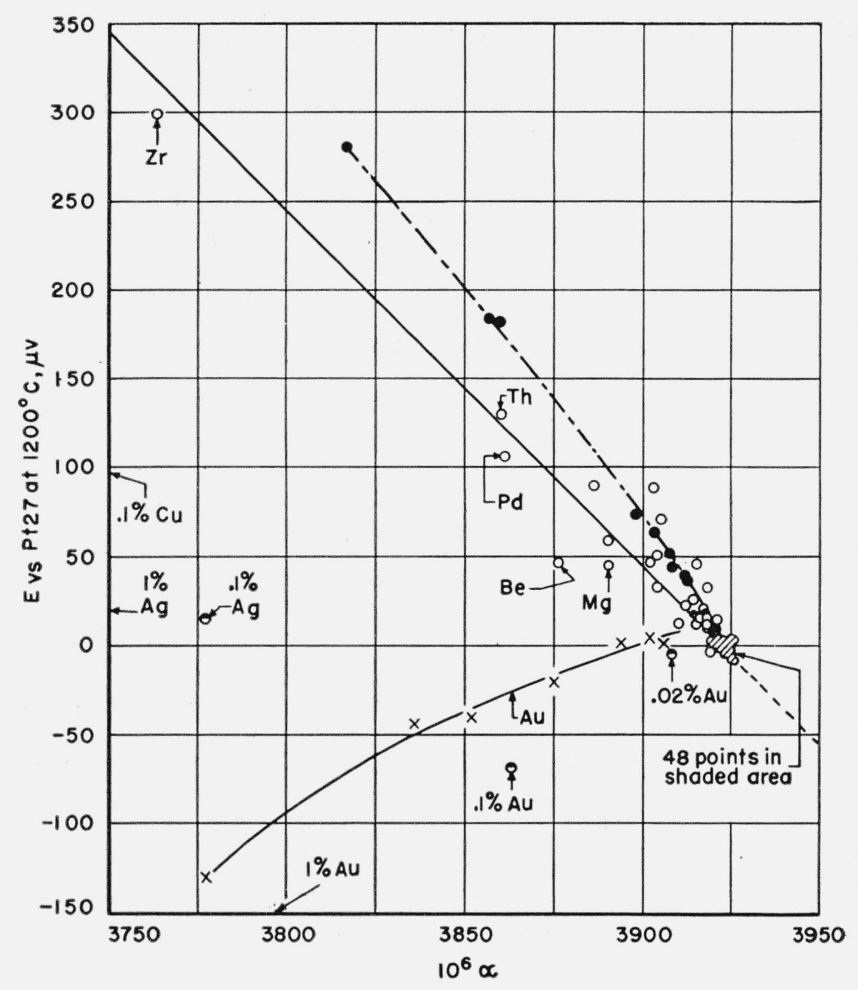

Figure 4. Electrical properties of platinum and various alloys. $\bigcirc$, Annealed samples of various purities. Where a given impurity was known to predominate its chemical symbol is given. $X$, Data of Wm. F. Roeser on alloy with gold (see table 3); $\boldsymbol{\Theta}$, data on alloys with gold and silver-this investigation; , data for hard-drawn platinum in various stages of annealing. (See table 1, amples 5 and 7 and table 5). The diagonal solid line represents the equation

$$
\alpha=0.003922-0.5 \times 10^{-6} E_{0}^{1.200^{\circ} \mathrm{C}} \mathrm{C} . \mathrm{Pt} .-27 .
$$

possible to judge to what extent the equation is generally valid. These samples with predominant single impurities are separately identified in figure 4. Because there is no reason to suppose that the effect of different impurities on the relation between $\alpha$ and $E$ is the same, the above equation ought to be used with caution. In fact, the effect of gold as an impurity is known to be entirely different. While addition of gold lowers $\alpha$ in the usual way, it makes the thermal emf more negative. This is illustrated by the lowest curve in figure 4 , which represents unpublished data obtained by Wm. F. Roeser in 1935 (table 3 ). The points are shown by crosses.

The change of electrical properties with time at $1,500^{\circ}$ is believed to be due to preferential volatiliza-

TABLE 3. Electrical properties of platinum containing small amounts of gold

\begin{tabular}{|c|c|c|}
\hline & $\alpha$ & 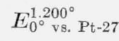 \\
\hline $\begin{array}{l}\text { Platinum containing } 0.25 \% \text { gold; initial } \\
\text { values } \\
\text { After } 3 \mathrm{hr} \text { at } 1,500^{\circ} \mathrm{C} \\
\text { After } 5 \mathrm{hr} \text { total at } 1,500^{\circ} \\
\text { After } 8 \mathrm{hr} \text { total at } 1,500^{\circ} \\
\text { After } 12 \mathrm{hr} \text { total at } 1,500^{\circ} \\
\text { After } 16 \mathrm{hr} \text { total at } 1,500^{\circ} \\
\text { After } 22 \mathrm{hr} \text { total at } 1,500^{\circ}\end{array}$ & $\begin{array}{r}0.03777 \\
.003836 \\
.003852 \\
.003875 \\
.003894 \\
.003906 \\
.003902\end{array}$ & $\begin{array}{r}\mu v \\
-131 \\
-44 \\
-40 \\
-20 \\
+2 \\
+2 \\
+5\end{array}$ \\
\hline
\end{tabular}

tion of gold. Spectrochemical analysis of the sample at the end of the experiment showed that the gold content had been reduced to 0.02 percent. (The sample also contained 0.01 percent of $\mathrm{Zr}$ at both start and finish plus traces of $\mathrm{Ca}, \mathrm{Al}, \mathrm{Mg}, \mathrm{Si}$, and $\mathrm{Fe}$. These impurities probably account for the final values of $E_{0^{\circ}}^{1200^{\circ}}{ }_{\mathrm{vs}, \mathrm{Pt}-27}$ being positive.)

Mott ${ }^{7}$ has explained some of the properties of palladium in terms of the quantum theory of metals and his discussion may be applied to platinum, which has a similar electronic structure. The explanation of the effect of dissolved gold in making the thermoelectric power of platinum more negative is particularly interesting in view of the singularity of this effect. However, it appears that copper and silver, being isoelectronic with gold should produce a similar effect. In order to test this, the electrical properties of a number of alloys of gold, silver and copper with platinum were determined. ${ }^{8}$ The data obtained and descriptions of the alloys are given in table 4 . The alloys were in the form of 0.020 -in.diameter wire and were annealed for $5 \mathrm{~min}$ at $1,450^{\circ} \mathrm{C}$ in air before testing.

The data in table 4 have been plotted in figure 4 , insofar as the range of the plot allows, and are represented by half-shaded circles. The isolated position of "Ag" in figure 4 is a consequence of the decrease of thermal emf of the silver alloys at the higher temperatures. The positive emf of the copper and silver alloys is contrary to prediction. Thus, gold remains the only impurity that has been found to lower the thermoelectric power of platinum.

The data for samples 5 and 7 in the hard-drawn state fall far outside the range of figure 3 but would

${ }^{7}$ N. F. Mott, The resistance and thermoelectric properties of the transition metals, Proc. Roy. Soc. (London). [A]156, 368 (1939). The characteristic feature of the transition metals on which this treatment is based, is the existence of a nearly filled $d$-hand overlapped by an $s$-band. The treatment of the effect of impurities on the thermoelectric power has been extended to aluminum by J. K. Galt, Phil. Mag. [7] 40, 309 (1949).

${ }_{8}$ The measurements of thermal emf were made by Henry Shenker.

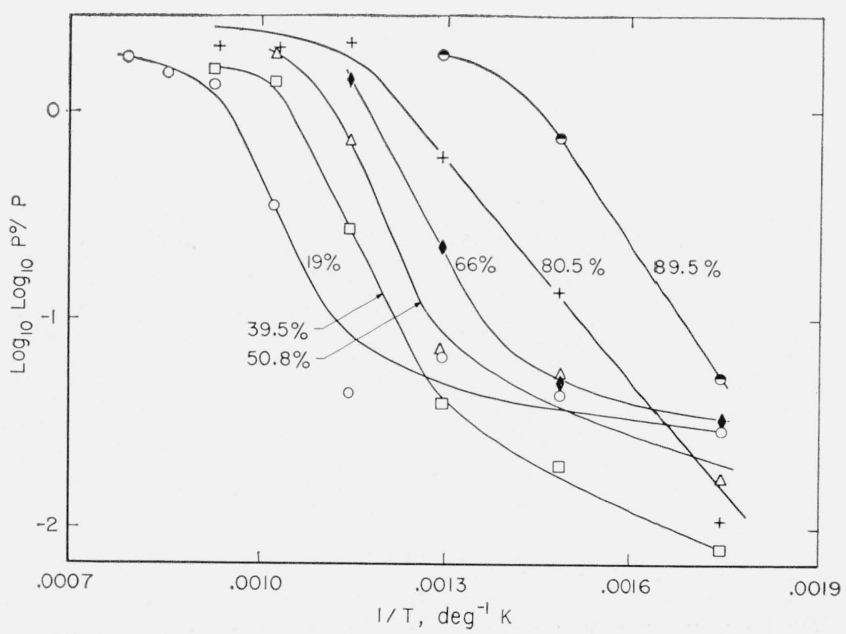

Figure 5. Data of Wise and Vines on isochronal annealing of platinum

Number give the percentage thickness-reduction in rolling. $P$ is the hardness number at temperature $T$ minus the hardness number of the fully annealed sample. $P_{0}$ is the value of $P$ before annealing. 
TABLE 4. Electrical properties of some platinum alloys

\begin{tabular}{|c|c|c|c|c|c|c|c|}
\hline \multirow{2}{*}{$\begin{array}{l}\text { Nominal } \\
\text { composition }\end{array}$} & \multirow{2}{*}{$\alpha$} & \multicolumn{6}{|c|}{$E_{0^{\circ}}^{t}$ vs. $\mathrm{Pt}-27$} \\
\hline & & $t=200^{\circ} \mathrm{C}$ & $t=400^{\circ} \mathrm{C}$ & $t=600^{\circ} \mathrm{C}$ & $t=800^{\circ} \mathrm{C}$ & $t=1000^{\circ} \mathrm{C}$ & $t=1200^{\circ} \mathrm{C}$ \\
\hline $\begin{array}{l}\text { Weight } \% \\
\mathrm{Pt}-0.1 \% \mathrm{Cu} \\
\mathrm{Pt}-1.0 \% \mathrm{Cu} \\
\mathrm{Pt}-5.0 \% \mathrm{Cu}\end{array}$ & $\begin{array}{l}0.003590 \\
.001938 \\
.0005375\end{array}$ & $\begin{array}{c}\mu v \\
+29 \\
234 \\
429\end{array}$ & $\begin{array}{l}\mu v \\
+67 \\
538 \\
1071\end{array}$ & $\begin{array}{r}\mu v \\
+100 \\
822 \\
1751\end{array}$ & $\begin{array}{c}\mu v \\
+129 \\
1085 \\
2489\end{array}$ & $\begin{array}{c}\mu v \\
+155 \\
1348 \\
3299\end{array}$ & $\begin{array}{c}\mu v \\
+183 \\
1625 \\
4211\end{array}$ \\
\hline $\begin{array}{l}\mathrm{Pt}-0.1 \% \mathrm{Ag} \\
\mathrm{Pt}-1.0 \% \mathrm{Ag}\end{array}$ & $\begin{array}{l}.003777 \\
.002797\end{array}$ & $\begin{array}{l}11 \\
86\end{array}$ & $\begin{array}{r}18 \\
152\end{array}$ & $\begin{array}{r}21 \\
177\end{array}$ & $\begin{array}{r}20 \\
170\end{array}$ & $\begin{array}{r}18 \\
148\end{array}$ & $\begin{array}{r}15 \\
126\end{array}$ \\
\hline $\begin{array}{l}\mathrm{Pt}-0.02 \% \mathrm{Au} \\
\mathrm{Pt}-0.1 \% \mathrm{Au} \\
\mathrm{Pt}-1.0 \% \mathrm{Au}\end{array}$ & $\begin{array}{l}.003908 \\
.003863 \\
.003404\end{array}$ & $\begin{array}{c}0 \\
-10 \\
-86\end{array}$ & $\begin{array}{r}-1 \\
-21 \\
-185\end{array}$ & $\begin{array}{r}-2 \\
-32 \\
-293\end{array}$ & $\begin{array}{r}-2 \\
-45 \\
-407 \\
\end{array}$ & $\begin{array}{r}-3 \\
-57 \\
-521\end{array}$ & $\begin{array}{r}-4 \\
-68 \\
-631\end{array}$ \\
\hline
\end{tabular}

lie somewhat above the extended line of eq 1 . The equation is represented in figure 3 by the diagonal line and is seen to represent the data on quenching of sample 4. The data on the quenching of sample 7 (items $\mathrm{K}$ through $\mathrm{Q}$, table 1 ) are also closely represented by eq 1 . However, the data on coldworking by coiling followed by annealing at temperatures below $1,450^{\circ}$ would lie above the line representing the equation in figure 3.

It is seen, therefore, that eq 1 is a good representation of the relation between $\alpha$ and $E$ for (a) pure platinum quenched at various rates and (b) annealed platinum, which is contaminated by various impurities other than gold, silver, and copper. ${ }^{9}$ The equation is only approximately correct for cold-worked platinum that has not been annealed at $1,450^{\circ} \mathrm{C}$.

Kinetics of annealing. Krupkowski and Balicki [11], Balicki [12], and Brindley [13] have shown that many features of the annealing process for copper can be interpreted in terms of the kinetics of a first-order process. In this theory it is postulated that the rate of annealing, $-d x / d t$, is proportional to $x$, which is the fraction of cold-worked metal remaining at time $t$, and to a factor $e^{-Q / R T}$, in which $Q$ is an activation energy. It is assumed further, that the quantity $P$, defined as the difference between the value of some property (resistivity, thermoelectric power, hardness, etc.) at a given stage of annealing and in the fully annealed state is proportional to $x$. That is,

$$
-\frac{d x}{d t}=c x e^{-Q / R T}
$$

${ }^{9}$ Relations between $\alpha$ and $E$ of similar form exist for silver and iron of relatively high purity. The following equations are derived from unpublished work at this Bureau by Wm. F. Roeser. $E$ is in microvolts.

$$
\begin{aligned}
& \text { Ag: } \alpha=0.00409-6 \times 10^{-6}\left(E_{0^{\circ}}^{100^{\circ}} \text { vs. Pt-27 }-730\right) \\
& \text { Fe: } \alpha=0.00651+4.8 \times 10^{-6}\left(E_{0^{\circ}}^{100^{\circ}} \text { vs. Pt-27 }-1980\right) .
\end{aligned}
$$

The values 0.00409 and 0.00651 are the maximum values of $\alpha$ obtained for silver and iron, respectively, and correspond to the purest samples in the annealed state. With silver, strain or decrease of purity resulted in decreased $\alpha$ and increased $E$ as was the case with platinum, while with iron, $\alpha$ and $E$ decreased together. Here, again, the consistency of the results for samples of different purity was probably fortuitous or due to the narrowness of sample selection. In Mott's probably fortuitous or due to the narrowness of sample selection. In Mott's
theory the positive sign of the coefficient of $E$ in the equation for iron, would be theory the positive sign of the coefficient of $E$ in the equation for iron, would be
related to the fact that $\partial \mathrm{N}(\boldsymbol{\epsilon}) / \partial \epsilon$ is positive for iron (J. C. Slater, Phys. Rev. 49 $537(1936)$, where $N(\epsilon)$ is the number of $d$-levels of energy $\epsilon$. This is in contrast to platinum for which the coefficient of $E$ and the quantity $\partial N(\epsilon) / \partial \epsilon$ are both negative. Matthiessen's rule was obeyed throughout the range of purity and coldwork covered by these experiments, namely, down to values of $\alpha$ of 0.00387 for silver and 0.00542 for iron. where $c$ is a constant, and $P \propto x$, whence

$$
\frac{P}{P^{\circ}}=e^{-c t e^{-Q / R T}}
$$

where $P^{\circ}$ is the value of $P$ at $t=0$. On the other hand, Cook and Richards [14], in order to arrive at a form of equation that would fit their hardness measurements on cold-rolled copper, found it necessary to assume a two-step process, namely, "recovery" followed by "recrystallization". Richards states ". . . it is assumed that the degree of recovery is always very small, our conception is that recovery is shorter in range than recrystallization and small recovered regions serve as points at which recrystallization can commence". The result of this treatment is a formula similar to eq 3 , except that $t$ appears squared and in place of $Q$ there appears the sum of the activation energies for recovery and recrystallization. Values of $Q$ for copper in the range 11.5 to $33 \mathrm{kcal} / \mathrm{mole}$ (0.5 to $1.4 \mathrm{ev})$ have been reported.

A test of the applicability of these equations to the data on the annealing of platinum by Wise and Vines [2] is illustrated in figure 5. (The annealing procedure of these authors may be termed "isochronal", since annealing was carried out for a fixed time at various temperatures.)

As figure 5 shows, the data are apparently incompatible with eq 3 and with Cook and Richards' equation, both of which require that the lines be straight. From the slopes of the straight midportions of the curves are derived values of $Q$ ranging from 16 to $31 \mathrm{kcal} / \mathrm{mole}$ without any obvious dependence on the percentage of reduction. It is difficult to base any interpretation on these data, because for each curve there is only one point at or near half-recovery. All the other hardness values are within a few hardness numbers of either the initial or final values, and hence $\log P^{\circ} / P$ has low accuracy at these points.

In order to test eq 3 further, two isothermal annealing curves for platinum were obtained experimentally The samples were from the same stock as sample 7 . Measurements of the coefficient of resistance, $\alpha$, and of the thermal emf $E_{0^{\circ}}^{10{ }^{\circ} \mathrm{C}}$ versus the same annealed reference wire used previously were made in the same way as before, except that the lead, AX (fig. 1), was a length of annealed wire similar thermoelectrically 
TABLE 5. Annealing of hard-drawn platinum wire

\begin{tabular}{|c|c|c|c|c|c|c|c|}
\hline \multirow{2}{*}{$\begin{array}{l}\text { Total } \\
\text { time, } t\end{array}$} & \multirow[b]{2}{*}{$R_{0}$} & \multirow[b]{2}{*}{$R_{100}-R_{0}$} & \multirow[b]{2}{*}{$\alpha$} & \multirow{2}{*}{$E_{0^{\circ}}^{100^{\circ} \mathrm{C}}$ v8 ref } & \multicolumn{3}{|c|}{$P / P^{\circ}$} \\
\hline & & & & & $\begin{array}{l}\text { From } \\
E_{0^{\circ}}^{100^{\circ}}\end{array}$ & $\begin{array}{l}\text { From } \\
\alpha\end{array}$ & $\begin{array}{l}\text { From } \\
P_{0}\end{array}$ \\
\hline \multicolumn{8}{|c|}{ Sample No. 9 , annealed at $301^{\circ} \mathrm{C}$} \\
\hline $\begin{array}{l}h r \\
0 \\
0.17 \\
.50 \\
1.5 \\
5.5 \\
29.5 \\
151 .\end{array}$ & $\begin{array}{c}\text { Ohm } \\
0.188000 \\
.187752 \\
.187563 \\
.187318 \\
.186761 \\
.186640\end{array}$ & $\begin{array}{c}\text { Ohm } \\
0.073281 \\
.073288 \\
.073290 \\
.073289 \\
.073285 \\
.073282\end{array}$ & $\begin{array}{r}\alpha 0.003857 \\
.0038979 \\
.0039034 \\
.0039075 \\
.0039125 \\
.0039240 \\
.0039264\end{array}$ & $\begin{array}{r}\mu v \\
\alpha+15.9 \\
6.7 \\
5.9 \\
4.9 \\
3.6 \\
.6 \\
.0\end{array}$ & $\begin{array}{l}1 \\
0.42 \\
.37 \\
.30 \\
.23 \\
.04 \\
0\end{array}$ & $\begin{array}{l}1 \\
0.41 \\
.33 \\
.27 \\
.20 \\
.03 \\
0\end{array}$ & $\begin{array}{l}1 \\
0.41 \\
.33 \\
.28 \\
.20 \\
.04 \\
0\end{array}$ \\
\hline \multicolumn{8}{|c|}{ Sample No. 8 , annealed at $352^{\circ} \mathrm{C}$} \\
\hline $\begin{array}{l}0 \\
0.13 \\
.27 \\
1.23 \\
6.2 \\
31.2\end{array}$ & $\begin{array}{r}0.196363 \\
.193851 \\
.193680 \\
.193236 \\
.192973 \\
.192958\end{array}$ & $\begin{array}{r}0.075737 \\
.075761 \\
.075762 \\
.075761 \\
.075761 \\
.075763\end{array}$ & $\begin{array}{c}0.003857 \\
.0039082 \\
.0039117 \\
.0039206 \\
.0039260 \\
.0039264\end{array}$ & $\begin{array}{r}+15.9 \\
4.2 \\
3.9 \\
1.3 \\
0.2 \\
.1\end{array}$ & $\begin{array}{l}1 \\
0.26 \\
.24 \\
.08 \\
.01 \\
0 .\end{array}$ & $\begin{array}{l}1 \\
0.26 \\
.21 \\
.08 \\
.01 \\
0\end{array}$ & $\begin{array}{l}1 \\
0.26 \\
.21 \\
.08 \\
.00 \\
0\end{array}$ \\
\hline
\end{tabular}

n Not determined experimentally. Values assumed to be the same as for the sample used at $352^{\circ}$.

to the reference wire, CY. This placed the effective cold junction of the thermocouple, AXYC, at point X. (The temperature of this point was measured by replacing $\mathrm{BX}$ with a platinum 10-percent rhodium wire and measuring the emf of the platinum-platinum 10-percent rhodium thermocouple, BXA. This procedure avoided bringing inhomogeneous wire into the region of temperature gradient during the measurements. Samples were annealed at $301^{\circ}$ and $352^{\circ}$ C. The results are given in table 5 .

Values of $12{E_{0^{\circ}}^{100^{\circ}} \mathrm{C}}$ are plotted versus $\alpha$ as filled circles in figure 4 for the samples annealed at $301^{\circ}$ and $352^{\circ} \mathrm{C}$. The dashed curve drawn through these points also represents the data for samples 5 and 7 (table 1) in the hard-drawn state and for sample 7 after coiling.

Table 5 shows that there is little difference whether $P / P^{\circ}$ refers to changes in $R_{0}, \alpha$, or $E$. Values of $P / P^{\circ}$ calculated from $\alpha$ are plotted in figure 6 .

Two noteworthy features of the data may be pointed out: (1) the marked decrease in $P / P^{\circ}$ in the first few minutes is much greater than is required by a simple exponential dependence on $t$, that is eq 3

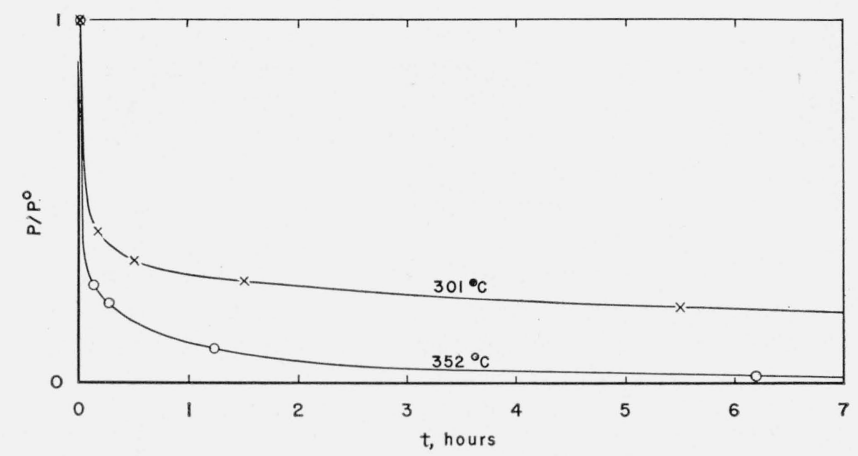

Figure 6. Isothermal annealing of two samples of hard-drawn platinum

Values of $P / P^{0}$ were calculated from changes in $\alpha$ (table 5). and the equation of Cook and Richards do not apply, (2) the limiting values that $\alpha$ and $E$ approach as $t$ increases are the same regardless of the annealing temperature. Others (see footnote 5 and reference [13]) have found the limiting values to be a function of the annealing temperature. Since the present experiments are distinguished by the very high purity ${ }^{10}$ of the samples used, it is suggested that the dependence of limiting value on temperature that others have found may be due to the presence of impurities.

We may picture annealing to be the result of diffusion of dislocations and their cancellation through encounters with dislocations of opposite sign. If this were the case, the rate of recombination would be proportional to the square of the concentration of dislocations and to their diffusion velocity. The latter would contain a factor, $e^{-Q / R T}$, in which $Q$ may be regarded as an activation energy for a displacement over a distance of one atomic diameter. Assuming further that $P$ is proportional to the concentration of dislocations, the equation

$$
\frac{P^{\circ}-P}{P}=k t e^{-Q / R T}
$$

is obtained. This equation, however, also fails to fit the experimental data. According to the above mechanism, we may suppose that the final stages of annealing (when the local density of dislocations is everywhere low) would be the same regardless of whether the metal had been initially cold-worked to a high degree or not. This is at variance with a body of evidence $[2,13,14]$ showing that the final stages of annealing are slower the less the amount of prior cold-work.

Returning to Cook and Richards' assumption of an intermediate stage, the mathematics for such a

10 Spectrochemica analysis and other considerations indicated that the total content of impurities did not exceed 10 parts per million, and probably was much less. 
two-step process may be carried through rigorously, that is without these author's assumption that the extent of the primary process is always small. The result of this treatment is that $P / P^{\circ}$ is equal to the sum of two exponential terms, each having the form of the right side of eq 3 . Indeed, the curves of figure 6 can be fitted by sums of a number of exponential terms of the form of eq 3 . However, at least three terms are required to fit the upper curve. Since Brindley [13] and Balicki [12] have shown that $Q$ for copper is practically independent of the degree of cold-work, it seems reasonable to inquire whether the present data might be fitted by summing terms like the right side of eq 3 over a range of values of $c$ while taking $Q$ to be constant. Proceeding in this way we have

$$
P=\int_{0}^{c_{m}} p^{\circ} e^{-c t e^{-Q / R T}} f(c) d c,
$$

where $f(c)$ expresses the density of the terms $p^{\circ} e^{-c t e^{-Q / R T}}$ as a function of $c$. Depending on the form of $f(c), c_{m}$ may be either finite or infinite.

Simple functions such as $f(c)=a c^{n} e^{-b c} ; n>0, b>0$ did not lead to a representation of the data, but the saddle-shaped function

$$
f(c)=m e^{-a c}+q c e^{-b c}
$$

gave a satisfactory result. $a, b, m$, and $q$ are constants. Inserting this function in eq 4 and integrating to $c_{m}=\infty$ gave

$$
\frac{P}{P^{\circ}}=\frac{k_{1}}{1+\frac{t e^{-Q / R T}}{a}}+\frac{k_{2}}{\left(1+\frac{t e^{-Q / R T}}{b}\right)^{2}}
$$

where $k_{1}=m p^{\circ} / a P^{\circ}$, and $k_{2}=q p^{\circ} / b^{2} P^{\circ}$. The second term describes the decrease in $P / P^{\circ}$ at small values of $t$, the first term remaining constant at the value, $k_{1}$. With further increase of $t$, the first term, which by now predominates, also decreases. The agreement was improved by taking the limiting value of $\alpha$ to be 0.0039274 instead of 0.0039264 . In calculating $Q$ from the values of the constants at the two temperatures, one finds that different values result in each term of eq 5 . The resulting constants are $k_{1}=0.328$, $k_{2}=0.672, a=1.4 \times 10^{-14} \mathrm{hr}, b=2.9 \times 10^{-9} \mathrm{hr}, Q_{1}=39$ $\mathrm{kcal} / \mathrm{mole}, Q_{2}=20 \mathrm{kcal} /$ mole. $^{11}$

${ }_{11}$ After this paper had been prepared, C. H. Meyers kindly furnished the author with unpublished data on the annealing of hard-drawn platinum wire at $100^{\circ}$ and $530^{\circ} \mathrm{C}$. The samples used were $0.003-\mathrm{in}$. wire from the same lot as sample 5. At $100^{\circ} \mathrm{C}$, only the initial part of the annealing was observed (to $P / P^{\circ}=0.93$ at $t=11 \mathrm{hr}$.) This change in $P / P^{\circ}$ is given by the second term of $P / P^{\circ}=0.93$ at $t=11 \mathrm{hr}$. This change in $P / P^{\circ}$ is given by the second term of eq 5, the first term remaining constant at the value $k_{1}=0.328$. On the other $P / P^{\circ}=0.008$ at $t=0.146 \mathrm{hr}$ ). This change is given by the first term of eq 5 , the second term being already zero. It was found that eq 5 with the constants given abovo did not represent these data. However, by altering the constants to the values, ()$_{1}=28 \mathrm{kcal} / \mathrm{mole}, O_{2}=16 \mathrm{kcal} / \mathrm{mole}, a=1.4 \times 10^{-10} \mathrm{hr}, b=8.1 \times 10^{-8} \mathrm{hr}$, these dat were well representer. This change introduced systematic differences between the calculated and observed values of $\alpha$ at $301^{\circ}$ and $352^{\circ} \mathrm{C}$ that were as large as $2 \times 10^{-6}$. Thus, using the altered constants, the representation by eq 5 of all the annealing data from $100^{\circ}$ to $530^{\circ} \mathrm{C}$ is fairly good, although somewhat outside the range of experimental error.
Whether or not eq 5 is generally valid, we may at least conclude that it is apparently not possible to fit the curves of figure 6 on the basis of temperatureactivated processes having a single value of $Q$. It may be supposed that $Q$ depends upon the local stress existing in the region of a given dislocation. A complete treatment, taking $d n$ in eq 4 to be a function of both $c$ and $Q$ has not been carried out, since a larger body of experimental data would be required in order to establish the form of the required function.

Several helpful discussions with Bert Brenner, of the Sigmund Cohn Corp., are acknowledged, and the cooperation of that concern in supplying the samples of platinum for these experiments is much appreciated.

\section{References}

[1] H. F. Stimson, The International Temperature Scale of 1948, J. Research NBS 42, 209 (1949) RP1962.

[2] E. M. Wise and R. F. Vines, Effect of cold-work upon hardness and recrystallizing behavior of pure platinum, Trans. Am. Inst. Min. Met. Eng. 137, 464 (1940).

[3] G. Tammann and K. L. Dreyer, Ann. Phys. [5] 16, 111 (1933).

[4] G. Tammann and G. Bandel, Ann. Phys. [5] 16, 120 (1933).

[5] O. Feussner, Metallwirtschaft 7, 470 (1928); see also, R. F. Vines, The platinum metals and their alloys, p. 31 (The International Nickel Co., Inc., New York, N. Y., 1941).

[6] Wm. F. Roeser and H. T. Wensel, Methods of testing thermocouples and thermocouple materials, J. Research NBS 14, 253 (1935) RP768; also Temperature, its measurement and control in science and industry, p. 289 (Reinhold Publishing Corp., New York, N. Y., 1941).

[7] Bert Brenner, Changes in platinum thermocouples due to oxidation, chapter in Temperature, its measurement and control in science and industry, p. 1281 (Reinhold Pub. Corp., New York, N. Y., 1941).

[8] W. Matthiessen and C. Vogt, Pogg. Ann. 122, 47 (1864).

[9] See for example, H. H. Uhlig, ed., Corrosion Handbook, p. 700 (John Wiley \& Sons, Inc., New York, N. Y., 1948).

[10] H. A. Jones, I. Langmuir, and G. M. J. Mackay, Phys. Rev. 30, 201 (1927).

[11] A. Krupkowski and M. Balicki, Rev. de Metallurgie, Memoires 36, 21 (1939).

[12] M. Balicki, J. Iron \& Steel Inst. 151, 181 (1945).

[13] G. W. Brindley, Report of a Conference on Strength of Solids, p. 95 published by The Physical Society, London (1948).

[14] M. Cook and T. Ll. Richards, J. Inst. Metals 73, 1, and discussion p. 705 (1946).

Washington, November 29, 1950. 